CoFE discussion papers ; 05/05

\title{
Return Predictability and Stock Market Crashes in a Simple Rational Expectations Model*
}

\author{
Günter Franke ${ }^{\dagger}$ and Erik Lüders ${ }^{\ddagger}$
}

This draft: September 21, 2005

\footnotetext{
${ }^{*}$ We are grateful to Axel Adam-Müller, Yacine Ait-Sahalia, Yakov Amihud, Andrew Ang, Menachem Brenner, Antonio Camara, Peter Carr, Damien Chabi-Yo, David Feldman, Stephen Figlewski, Jens Jackwerth, Tao Lin, Harris Schlesinger, Sophie Shive, Siegfried Trautmann, Hongjun Yan and Robert Whitelaw for helpful discussions. We also thank Jens Jackwerth for providing us data on empirical risk aversion functions. Comments from seminar participants at the GEABA Meeting in Berlin, the Symposium on Finance, Banking and Insurance in Karlsruhe, the MFA 2003 Meeting in St. Louis, the EFA 2003 Meeting in Lake Buena Vista, the 2003 Meeting of the Verein für Socialpolitik in Zurich, the FMA 2003 Meeting in Denver, the NFA 2003 Meeting in Quebec, the EFMA 2004 Meeting in Basle, the ESEM 2004 in Madrid, the EFA 2005 Meeting in Moscow and at Concordia University, the University of Konstanz, Laval University, McMaster University, New York University and Syracuse University have been helpful to us. Financial support by the Institut de Finance Mathématique de Montréal, the CoFE (University of Konstanz), the ZEW (Mannheim) and a grant by the Deutsche Bundesbank are gratefully acknowledged.

${ }^{\dagger}$ University of Konstanz, e-mail: guenter.franke@uni-konstanz.de

${ }^{\ddagger}$ Pinehill Capital and Laval University, e-mail: erik.lueders@pinehillcapital.com
} 


\begin{abstract}
This paper presents a simple rational expectations model of intertemporal asset pricing. It shows that heterogeneous risk aversion of investors is likely to generate declining aggregate relative risk aversion. This leads to predictability of asset returns and high and persistent volatility. Stock market crashes may be observed if relative risk aversion differs strongly across investors. Then aggregate relative risk aversion may sharply increase given a small impairment in fundamentals so that asset prices may strongly decline. Changes in aggregate relative risk aversion may also lead to resistance and support levels as used in technical analysis. For numerical illustration we propose an analytical asset price formula.
\end{abstract}

JEL classification: G12

Keywords: Aggregate relative risk aversion, Equilibrium asset price processes, Excess Volatility, Return predictability, Stock market crashes 
Empirical research suggests that returns of broad based market indices as the S\&P 500 are predictable. This seems to contradict the efficient market hypothesis. While it is controversial whether the predictability in returns is economically significant - especially concerns related to data-snooping are often expressed - studies on return volatility provide clear evidence against constant volatility and therefore against the geometric Brownian motion of asset prices. An extensive literature on excess volatility which was started by Shiller (1981) and LeRoy and Porter (1981) claims that the volatility of asset prices is too high to be consistent with classical asset pricing models. Moreover, the occurrence of stock market crashes without any significant news and the widespread use of technical analysis are often claimed to be incompatible with rational, efficient markets. ${ }^{1}$ To explain these findings many researchers argue in favor of investor irrationality and new behavioral postulates. Other explanations rely on market imperfections such as information costs which may explain herding and positive feedback trading.

Neither "irrational" behavior nor market imperfections are needed to explain these characteristics. In this paper we show that a simple rational expectations model based on a perfect capital market can explain these asset price characteristics if aggregate relative risk aversion is declining. If there exists a representative investor, then her relative risk aversion would equal aggregate relative risk aversion (Rubinstein, 1974). In this paper no representative investor exists. Then aggregate relative risk aversion depends on the equilibrium allocation and the relative risk aversion levels of the various investors. The level and variation of aggregate relative risk aversion is controversial. Defining aggregate relative risk aversion as the negative elasticity of the stochastic discount factor with respect to the asset price, recent empirical studies estimate its level using option prices. The empirical results documented in Ait-Sahalia and Lo (2000), Jackwerth (2000) and Rosenberg and Engle (2002) suggest extreme bounds for aggregate relative risk aversion. Ait-Sahalia and Lo (2000), for example, document levels up to 60 for S\&P 500 index values about 15 percent below the current future price. For the lower bound, the work by Jackwerth suggests even negative aggregate risk aversion, that is risk loving. ${ }^{2}$ But little is known on the level of aggregate relative risk aversion for index values more than 15 percent above or

\footnotetext{
${ }^{1}$ For an overview on return predictability and return volatility as well as a discussion of the methodological problems, see Campbell et. al. (1997) and Cochrane (2001). Ghysels et. al. (1996) provide an extensive overview on the characteristics of return volatility. Shiller (2000) provides evidence that stock market crashes may occur without significant news. For a recent study on the effectiveness of technical analysis see Lo et. al. (2000).

${ }^{2}$ Assuming constant aggregate relative risk aversion, Bliss and Panigirtzoglou (2003) estimate aggregate relative risk aversion levels between 1.97 and 9.52. They find that risk aversion declines with the forecast horizon and with the level of volatility. Analyzing the cross section of industry portfolios Dittmar (2002) also provides evidence against constant aggregate relative risk aversion.
} 
below the current future price and the empirical estimates are subject to various methodological concerns (see Barone-Adesi et. al. 2004, Bliss and Panigirtzoglou, 2003 and Hentschel, 2003). Also there is little consensus on risk aversion of individual investors. Most researchers agree, however, that investors display declining absolute risk aversion and that their risk aversion levels differ. The first important result in this paper is that under these conditions aggregate relative risk aversion is likely to decline. Therefore this paper analyzes asset price processes under declining aggregate relative risk aversion.

To analyze the effects of declining aggregate relative risk aversion on the characteristics of the market portfolio return, we consider a model similar to that of Brennan and Xia (2002) in which the dividend on the market portfolio is governed by a geometric Brownian motion and the price of the market portfolio equals the present value of these dividends. The price depends on aggregate relative risk aversion. Since the dividend is exogenously given, but prices are not, we prefer to define aggregate relative risk aversion as the negative elasticity of the stochastic discount factor with respect to the dividend. In an intertemporal model this allows us to characterize risk preferences independently of endogenous asset prices. If aggregate relative risk aversion is constant, then the market return is identically and independently distributed ruling out return predictability, excess volatility and stock market crashes. If, however, aggregate relative risk aversion declines with increasing concurrent dividend, then an increase in the dividend leads to an overproportional price increase because the risk premium declines. Similarly, if the dividend declines, then the stock price declines overproportionally because the risk premium increases. This implies excess volatility and predictability of market returns. If aggregate relative risk aversion declines rapidly in some dividend range, then the risk premium declines strongly in this range so that the price of the market portfolio increases rapidly given a small increase in dividends. Conversely, a small decline in dividends then leads to a strong price decline, similar to a crash. If the dividend happens to first increase and then to decline, then we may observe a stock market movement which resembles a bubble that bursts. In the language of technical analysis, the lower bound of this critical dividend range may be interpreted as the support level and the upper bound as the resistance level. We show that aggregate relative risk aversion may strongly decline with increasing dividend if relative risk aversion levels differ strongly across investors.

These important results are new as shown by a brief discussion of the theoretical asset pricing literature. For finite horizon models it is known from Bick (1990) and Franke et. al. (1999) that if the price of the market portfolio is governed by a geometric Brownian motion as in the Black and Scholes (1973) model, then aggregate relative risk aversion is constant. Bick (1990) and He and Leland (1993) derive characteristics of asset price processes which are 
consistent with an equilibrium driven by a representative investor. They show that such an equilibrium rules out widely used stochastic processes such as the Ornstein-Uhlenbeck process and constant elasticity of variance for market portfolio returns.

Many asset pricing models still assume constant aggregate relative risk aversion. Among the few papers which analyze the impact of aggregate relative risk aversion on return characteristics is Stapleton and Subrahmanyam (1990). They assume that the cash flow process is governed by a geometric [arithmetic] Brownian motion. They show that if aggregate relative risk aversion [absolute risk aversion] is constant, the forward price is governed by a geometric [arithmetic] Brownian motion. Franke et. al. (1999) show that option prices are higher for declining than for constant aggregate relative risk aversion and that asset returns are serially correlated in case of declining aggregate relative risk aversion. Neither Franke et. al. (1999) nor Stapleton and Subrahmanyam (1990) give a characterization of the volatility function or the autocorrelation function. Also, they do not provide any quantification of the effects of aggregate relative risk aversion on asset price process. Recent papers have analyzed the implications of heterogeneous preferences on aggregate relative risk aversion. Besides of Benninga and Mayshar (2000), Chan and Kogan (2002) analyze a continuous time-economy with a continuum of agents who have "catching up with the Joneses" preferences and differ in the level of constant relative risk aversion. Although they do not provide an analytical solution for asset prices, they show that this kind of heterogeneity can generate mean reversion in asset returns. None of these papers, however, provides any rationale for stock market crashes.

Related to this paper is the research on the effect of learning on return characteristics. Brennan and Xia (2002) assume that the representative investor cannot observe the growth rate of dividends but estimates it from realized data. Their model can explain high volatility of stock prices. Johnson (2002) builds on their results to show that stochastic expected growth rates of the dividend process lead to momentum. Brennan et. al. (2003) and Brennan and Xia (2003) also work within a similar framework. They emphasize the importance of a time-varying investment opportunity set to explain the predictability of asset returns. ${ }^{3}$

Summarizing, we still lack a sound understanding of asset return characteristics. This lack of knowledge exists even in the presence of the vast empirical literature on asset returns, part of which has been criticized by Ang and Liu (2004) for internal inconsistencies in asset return specifications.

The remainder of the paper is organized as follows. In Section 1 the model is introduced and declining aggregate relative risk aversion is shown to be the

\footnotetext{
${ }^{3}$ See also Timmermann (1993), David (1997), Veronesi (2000) and Pastor and Veronesi (2003) for the effect of learning on asset pricing.
} 
normal case. Moreover, the general relationship between aggregate relative risk aversion, the dividend and the price process of the market portfolio is derived. In Section 2, predictability of excess returns and excess volatility are shown. Section 3 discusses conditions for stock market crashes. In section 4 an analytic formula for the price of the market portfolio is presented together with simulations illustrating the previous results. Section 5 concludes.

\section{The Economic Setting}

Our aim is to analyze a simple model of investors preserving essential plausible properties of a rational expectations equilibrium. Since asset pricing depends on aggregate relative risk aversion, we first motivate our assumption that aggregate relative risk aversion is declining. Then we analyze the implications on asset pricing. We consider a pure exchange economy with a perfect and complete market. All agents have homogeneous and rational expectations, but different utility functions.

\subsection{Investor Heterogeneity and Aggregate Risk Aversion}

In this section we argue that declining aggregate relative risk aversion (RRA) is the normal case. Aggregate RRA is the market's relative risk aversion as implied by the stochastic discount factor (pricing kernel) by which claims to be paid at a given future date are valued in the capital market. ${ }^{4}$ In the case of risk neutrality the stochastic discount factor is constant. With risk aversion, the stochastic discount factor is declining in some aggregate variable like wealth or aggregate consumption. The negative elasticity of the discount factor with respect to this variable defines aggregate RRA. This variable is given in our model by the dividend of the market portfolio.

Aggregate RRA depends on investors' RRA. There is little disagreement that investors display declining absolute risk aversion. But it is controversial whether they display declining RRA. While it is therefore difficult to justify declining aggregate RRA in a representative investor economy (Rubinstein, 1974), we will show that declining aggregate RRA is likely to be observed if a representative investor does not exist. Consider the following setup. At each date $\tau$, aggregate consumption equals aggregate dividend $D_{\tau}$. Each agent, indexed by $i=1, \ldots, n$, has a time-additive von NeumannMorgenstern utility function. She has some initial endowment and trades in a perfect, complete market. She may consume at each future date. As

\footnotetext{
${ }^{4}$ Since in this paper we consider only the characteristics of the market portfolio, we do not differentiate between the pricing kernel and the asset specific pricing kernel. For a discussion, see Camara (2003).
} 
shown by Wachter (2002), in a complete market an investor with timeadditive utility over consumption allocates wealth as if she saves for every consumption date separately. Thus, the pricing of date $\tau_{1}$-claims can be analyzed independently of that of $\tau_{2}$-claims subject to the usual no-arbitrage requirement. At any date $t$, each agent can trade claims on aggregate consumption of date $\tau, \tau>t$. Let $x_{i}\left(D_{\tau}\right)$ denote the consumption of agent $i$ at date $\tau$ as a function of aggregate consumption $D_{\tau}$ and $\alpha_{i}\left(D_{\tau}\right)=x_{i} / D_{\tau}$ her share of consumption. Then $\sum_{i} \alpha_{i}\left(D_{\tau}\right)=1$ for every level of aggregate consumption. As shown by Benninga and Mayshar (2000), in equilibrium aggregate RRA $\eta_{M}\left(D_{\tau}\right)$ is related to the investors' RRA by the harmonic mean,

$$
1 / \eta_{M}\left(D_{\tau}\right)=\sum_{i}\left(1 / \eta_{i}\left(x_{i}\right)\right) \alpha_{i}\left(D_{\tau}\right)
$$

$\eta_{i}\left(x_{i}\right)$ is agent $i$ 's RRA given her consumption $x_{i}$. In order to find out whether aggregate RRA declines in aggregate consumption $D_{\tau}$, we differentiate equation (1) with respect to $D_{\tau}$. As shown in the appendix, we obtain the following result.

Lemma 1 The growth rate of aggregate $R R A$ is

$$
\begin{aligned}
\frac{\eta_{M}^{\prime}\left(D_{\tau}\right)}{\eta_{M}\left(D_{\tau}\right)} & =\sum_{i} \frac{\eta_{i}^{\prime}\left(x_{i}\right)}{\eta_{i}\left(x_{i}\right)}\left[\frac{\alpha_{i}\left(D_{\tau}\right)}{\eta_{i}\left(x_{i}\right)} \eta_{M}\left(D_{\tau}\right)\right]^{2} \\
& -\frac{\left[\eta_{M}\left(D_{\tau}\right)\right]^{2}}{D_{\tau}} \sum_{i} \alpha_{i}\left(D_{\tau}\right)\left[\frac{1}{\eta_{i}\left(x_{i}\right)}-\frac{1}{\eta_{M}\left(D_{\tau}\right)}\right]^{2}
\end{aligned}
$$

The lemma shows that in equilibrium the growth rate of aggregate RRA is the difference between two terms, the first being the sum of weighted growth rates of individual RRA, the second being a pseudo-variance of the inverse individual levels of RRA. If every investor has a positive share of consumption $\alpha_{i}\left(D_{\tau}\right)$, then, apart from $\left[\eta_{M}\left(D_{\tau}\right)\right]^{2} / D_{\tau}$, the last term in equation (2) has the properties of a variance term. The more heterogeneous agents are in their preferences and, hence, in their equilibrium levels of RRA, the higher is this pseudo-variance. It depends on the equilibrium allocation of consumption since the shares $\alpha_{i}\left(D_{\tau}\right)$ and the individual RRA $\eta_{i}\left(x_{i}\right)$ are endogenous.

Hence, as already shown by Benninga and Mayshar (2000), aggregate RRA is declining if every agent has constant RRA, i.e. if $\eta_{i}^{\prime}\left(x_{i}\right)=0$. Now suppose $\eta_{i}^{\prime}\left(x_{i}\right) \neq 0$. Then the first term on the right hand side of equation (2) multiplies the individual RRA growth rate $\eta_{i}^{\prime}\left(x_{i}\right) / \eta_{i}\left(x_{i}\right)$ by $z_{i}^{2} \equiv$ 
$\left[\alpha_{i}\left(D_{\tau}\right) \eta_{M}\left(D_{\tau}\right) / \eta_{i}\left(x_{i}\right)\right]^{2}$. Note that $\sum_{i} z_{i}=1$, by equation (1). Hence if there are many investors, each having a positive consumption share, then the average $z_{i}$ will be very small. This holds, a fortiori, for $z_{i}^{2}$. Therefore if there are investors with increasing, with constant and with declining RRA, then the first term on the right hand side is likely to be close to zero while the positive second term is subtracted. The second term tends to be higher, the more heterogeneous investor preferences are. ${ }^{5}$ Since this heterogeneity appears to be strong in reality, we conclude that aggregate RRA is likely to decline.

The intuition for this result can be obtained from the following reasoning. Given an optimal allocation of claims, a highly risk averse investor $i$ tends to buy claims $x_{i}\left(D_{\tau}\right)$ which increase only little with aggregate dividend $D_{\tau}$. Her demand curve $x_{i}\left(D_{\tau}\right)$ is rather flat. Hence her share $\alpha_{i}\left(D_{\tau}\right)=$ $x_{i}\left(D_{\tau}\right) / D_{\tau}$ tends to be high [low] when $D_{\tau}$ is low [high]. The opposite is true of an investor with low RRA. Therefore in the low dividend states the highly risk averse investors dominate the market so that aggregate RRA turns out to be high. In the high dividend states low risk averse investors dominate the market so that aggregate RRA turns out to be low. Thus, aggregate RRA tends to decline with increasing dividend. Hence, we regard declining aggregate RRA as the normal case and will analyze asset pricing for this case.

\subsection{The Pricing of the Market Portfolio}

We investigate the pricing of the market portfolio in a perfect and complete capital market. We consider a continuous time economy with an infinite horizon. Since we are interested in the pricing impact of declining aggregate RRA, we take the instantaneous risk-free rate $r_{f}$ as exogenously given and non-random. ${ }^{6}$ The market portfolio pays an exogenously given dividend stream which is governed by a geometric Brownian motion

$$
d D_{t}=\mu_{D} D_{t} d t+\sigma_{D} D_{t} d W_{t}, \quad 0 \leqslant t<\infty
$$

where the instantaneous drift $\mu_{D}$ and the instantaneous volatility $\sigma_{D}$ are assumed constant. $W_{t}$ is a one-dimensional standard Brownian motion and the initial dividend $D_{0}$ is positive. This represents a simple setting with the

\footnotetext{
${ }^{5}$ The second term approaches zero if one investor buys a very large fraction of the aggregate dividend and the other investors buy very little. This can happen if the aggregate dividend is very low or very high and marginal utility of consumption of the first investor relative to that of every other investor goes to infinity for very low resp. very high levels of consumption.

${ }^{6}$ The impact of heterogeneous time-preferences of investors on the term structure of interest rates is analyzed in Lengwiler (2004), for example.
} 
dividend being the only risk factor. The price of the market portfolio at date $t, S_{t}$, is the present value of all future dividends

$$
S_{t}=E\left(\int_{t}^{\infty} \exp \left(-r_{f}(s-t)\right) D_{s} \Phi_{t, s} d s \mid D_{t}\right) .
$$

This price is finite given a sufficiently high risk-free rate and aggregate risk aversion. $\exp \left(-r_{f}(s-t)\right) \Phi_{t, s}$ is the date t-stochastic discount factor for claims contingent on some state at date $s$. In an arbitrage-free, complete market this function is unique. Technically, $\Phi_{0, t}$ is a martingale and $\Phi_{t, s}=$ $\Phi_{0, s} / \Phi_{0, t}$. Since the dividend is the only risk factor in the market, $\Phi_{0, t}$ can be characterized by

$$
\begin{aligned}
d \Phi_{0, t} & =-\eta_{t}^{\Phi, D} \sigma_{D} \Phi_{0, t} d W_{t}, \\
\Phi_{0,0} & =1,
\end{aligned}
$$

where aggregate RRA is given by $\eta_{t}^{\Phi, D}$, the negative elasticity of the stochastic discount factor for claims to be paid at date $t$ with respect to the dividend $D_{t} \cdot{ }^{7}$ In this setting the asset price $S_{t}$ can be characterized by the following stochastic differential equation

$$
d S_{t}=\underbrace{\eta_{t}^{\Phi, D} \eta_{t}^{S, D} \sigma_{D}^{2} S_{t}-D_{t}+r_{f} S_{t}}_{=\mu_{S}\left(S_{t}\right) S_{t}} d t+\underbrace{\eta_{t}^{S, D} \sigma_{D} S_{t}}_{=\Sigma_{S}\left(S_{t}\right) S_{t}} d W_{t} .
$$

$\mu_{S}\left(S_{t}\right)$ denotes the instantaneous drift which equals the expected instantaneous excess return plus the risk-free rate $r_{f}$. $\Sigma_{S}\left(S_{t}\right)$ denotes the instantaneous volatility. Both, volatility and drift depend in general on the asset price $S_{t}$ and time $t$. For simplicity of notation we suppress the time index. $\eta_{t}^{S, D}$ denotes the elasticity of the asset price $S_{t}$ with respect to the dividend $D_{t}$.

\section{Predictability of Excess Returns and Excess Vola- tility}

We begin the analysis of return characteristics by looking at the elasticity of the asset price with respect to the dividend. If this elasticity is equal

\footnotetext{
${ }^{7}$ One way to interpret this stochastic discount factor is to assume that at each date aggregate consumption equals the aggregate dividend. Then the stochastic discount factor mirrors aggregate marginal utility of consumption. Alternatively, investors may use the aggregate dividend as an index of welfare with a higher index lowering the stochastic discount factor.
} 
to 1 , then the asset price also follows a geometric Brownian motion since the dividend is governed by a geometric Brownian motion. If the elasticity is higher than 1, then the spot price overreacts compared to a geometric Brownian motion. The following proposition establishes the relationship between the overreaction and aggregate RRA.

Proposition 1 (Overreaction)Assume that at each date aggregate RRA is declining in the dividend and that the dividend is governed by a geometric Brownian motion with constant instantaneous volatility and constant instantaneous drift. Then the elasticity of the asset price with respect to the dividend is higher than $1 .^{8}$

This proposition is proved in the appendix. To get the intuition for the overreaction, think about aggregate RRA in terms of RRA of a representative investor. A representative investor with decreasing RRA requires a lower excess return for the same risk, the wealthier he is, i.e. the higher the dividend is. Compared to an investor with constant RRA, her required risk premium decreases, the wealthier she is. Hence, the price she is willing to pay for the asset increases with increasing dividend more than under constant RRA. Thus, with declining aggregate RRA an increase in the dividend induces a decline in the required risk premium which reinforces the purely fundamental increase of the asset price so that the asset price overreacts compared to constant aggregate RRA. Similarly, a decline in the dividend induces an overproportional decline in the asset price.

To draw conclusions about the behavior of excess returns we need to derive the behavior of the total return index (performance index) $V_{t}$. Since the total return index includes the reinvested dividend payments, its return minus the risk-free rate is the excess return that we are interested in,

$$
\frac{d V_{t}}{V_{t}}-r_{f} d t=\frac{d S_{t}}{S_{t}}+\frac{D_{t}}{S_{t}} d t-r_{f} d t
$$

Note that $V_{t}=\alpha_{t} S_{t}$ with $\alpha_{t}$ being independent of $D_{t}$. Therefore $\frac{\partial \ln V_{t}}{\partial \ln D_{t}} \equiv$ $\eta_{t}^{V, D}=\eta_{t}^{S, D} \equiv \frac{\partial \ln S_{t}}{\partial \ln D_{t}}$. This implies that Proposition 1 holds equally for the elasticities $\eta_{t}^{S, D}$ and $\eta_{t}^{V, D}$. Hence, declining aggregate RRA implies that the total return index also overreacts. This overreaction translates into an increase in the instantaneous volatility of returns as the instantaneous volatility of the total return index is the product $\Sigma_{V}\left(S_{t}\right)=\eta_{t}^{V, D} \sigma_{D}$. This equals the instantaneous volatility of stock returns $\Sigma_{S}\left(S_{t}\right)=\eta_{t}^{S, D} \sigma_{D}$. The following proposition establishes that declining aggregate RRA also raises

\footnotetext{
${ }^{8}$ The corresponding result that asset returns underreact if aggregate RRA is increasing is shown in the appendix.
} 
the variance of asset returns over finite periods. Hence, declining aggregate RRA explains the well documented excess volatility.

Proposition 2 (Excess Volatility) Suppose that at each date aggregate RRA is declining in the dividend and that the dividend is governed by a geometric Brownian motion with constant instantaneous volatility and constant instantaneous drift. Then the conditional $(\tau>t=\theta)$ and the unconditional $(\tau>t>\theta)$ variance of the total return index exceed the dividend variance, i.e.

$$
\operatorname{Var}\left(\ln V_{\tau}-\ln V_{t} \mid D_{\theta}\right)>\operatorname{Var}\left(\ln D_{\tau}-\ln D_{t} \mid D_{\theta}\right)
$$

Proposition 2 is proved in the appendix. ${ }^{9}$ The conditional variance $\operatorname{Var}\left(\ln V_{\tau} \mid D_{t}\right)$ exceeds the dividend variance $\operatorname{Var}\left(\ln D_{\tau} \mid D_{t}\right)$ because of overreaction. The same is true of the unconditional variance. Therefore excess volatility is obtained.

We have seen that asset returns under declining aggregate RRA overreact compared to constant aggregate RRA. Does the overreaction render asset returns predictable? First, notice that the instantaneous drift of the total return index $\mu_{V}\left(S_{t}\right)$ equals the instantaneous drift of stock returns plus the dividend yield. Hence the instantaneous Sharpe ratio

$$
\frac{\mu_{V}\left(S_{t}\right)-r_{f}}{\Sigma_{V}\left(S_{t}\right)}=\frac{\mu_{S}\left(S_{t}\right)+\frac{D_{t}}{S_{t}}-r_{f}}{\Sigma_{S}\left(S_{t}\right)}=\eta_{t}^{\Phi, D} \sigma_{D}
$$

depends negatively on $D_{t}$ for declining aggregate RRA, $\eta_{t}^{\Phi, D}$. Therefore the Sharpe ratio can easily be predicted knowing the current dividend. The predictability of the Sharpe ratio would directly translate into predictability of excess returns if the instantaneous return volatility $\Sigma_{V}\left(S_{t}\right)$ was non-random. But changes in volatility might disturb this relationship, the exception being that the volatility does not increase with the dividend.

Instead of using the fundamental variable, in our model the dividend, for forecasting excess returns, many forecasts are based on past excess returns. This is successful if excess returns are either positively or negatively autocorrelated. To analyze the serial return dependence, we consider the covariance between the excess return over the time span $[t, \tau]$, i.e. $C E R_{t, \tau} \equiv \int_{t}^{\tau} \frac{d V_{s}}{V_{s}}-\int_{t}^{\tau} r_{f} d s$, and the instantaneous expected excess return at time $\tau$, i.e. $\mu_{V}(\tau)-r_{f} \cdot{ }^{10}$

\footnotetext{
${ }^{9}$ Proposition 2 assumes declining aggregate RRA. It does not hold in an analogous manner for increasing aggregate RRA.

${ }^{10}$ For a similar analysis see Johnson (2002).
} 
Proposition 3 (Predictability of asset returns) Suppose that at each date aggregate RRA is declining in the dividend and that the dividend is governed by a geometric Brownian motion with constant instantaneous volatility and constant instantaneous drift. Then, the cumulated excess return and the instantaneous expected excess return are negatively correlated if the volatility of excess returns does not increase with the dividend. ${ }^{11}$

This proposition is proved in the appendix. ${ }^{12}$ It shows that excess returns are negatively autocorrelated if aggregate RRA is declining, provided that the volatility of excess returns does not increase with the dividend. The intuition for the negative autocorrelation is that if past returns have been strongly positive, investors are better off implying lower aggregate RRA. Hence, the required risk premium decreases which lowers future expected excess returns. This leads to negative autocorrelation. However, Proposition 3 reveals that autocorrelation might be positive if the volatility of excess returns strongly increases with the dividend so that the required risk premium increases, too. This will be illustrated later in our simulations. To sum up, predictability of asset returns may be caused by declining aggregate RRA.

\section{Stock Market Crashes}

In this section we analyze aggregate RRA in more detail and provide an explanation for stock market crashes in our simple rational expectations model. Often a stock market crash like that at the beginning of this decade is associated with a previous price bubble. Such a bubble is created by a strong stock price increase which is not driven by a strong improvement in fundamentals, and a subsequent strong price decline aligning the stock price again to fundamentals. It is difficult to explain bubbles in a rational expectations framework. Many explanations are based on behavioral departures from "rationality" or market imperfections. The explanation of crashes in this paper relies neither on irrationality nor on market imperfections.

We define a crash as a situation in which a small decline in the fundamentals triggers a strong decline in the stock price. Conversely, a small improvement in the fundamentals may trigger a strong increase in the stock price. A bubble that bursts, thus, might be observed if a small improvement in fundamentals leading to a strong price increase is followed by a small decline in fundamentals leading to a strong price decline. Such phenomena will be shown to be fully consistent with a rational expectations equilibrium in a

\footnotetext{
${ }^{11}$ The corresponding result for increasing aggregate RRA is shown in the appendix.

${ }^{12}$ The conditions established in Proposition 3 are sufficient but not necessary.
} 
perfect market. Strongly declining aggregate RRA in a small range of fundamentals may be viewed as a shift from a high risk aversion regime to a low risk aversion regime or vice versa. This regime shift causes the crash.

To illustrate the regime shift, first, consider a market with constant aggregate RRA, $\bar{\eta}$. Then in an infinite horizon model in which the aggregate dividend follows a geometric Brownian motion, the stock price at date $t, S_{t}$, is a multiple of the dividend at date $t$,

$$
\begin{gathered}
S_{t}=\sum_{s=t}^{\infty} \frac{\mathrm{E}\left(D_{s} \mid D_{t}\right)}{(1+k)^{s-t}}=D_{t} \frac{1+k}{k} \\
\text { with } 1+k=\exp \left[r_{f}+\bar{\eta} \sigma_{D}^{2}-\mu_{D}\right] .
\end{gathered}
$$

To make things simple, suppose $r_{f}$ equals $\mu_{D}$. Then the price dividend ratio equals $\left[1-\exp \left(-\bar{\eta} \sigma_{D}^{2}\right)\right]^{-1}$. Empirical estimates of the dividend volatility of the market portfolio are around 12.8 percent. Then the price dividend ratio would be around 61.5 for constant aggregate RRA of 1 . Now suppose that unexpectedly aggregate RRA increases from a constant level of 1 to a constant level of 10 . Then the price dividend ratio would drop to 6.6, i.e. the price would drop by almost 90 percent. Hence the shift from the low to the high risk aversion regime induces a stock market crash. In the following, we analyze equilibria with the potential for a stock market crash.

The property required for a crash is that aggregate RRA stays almost constant in the range of low aggregate dividends, then drops sharply with an increase in dividends and, again, almost stays constant in the upper range. Even though a precise characterization of the conditions implying these properties is difficult, we present a condition implying that aggregate RRA almost stays constant for the low and the high supply range. Hence, in between, the (negative) slope must be strong so as to move down sufficiently. Given such a condition, we may observe a stock market crash. The result proved in the appendix assumes in line with the literature that all investors have constant RRA, but the level of RRA differs across investors.

Lemma 2 Consider an equilibrium allocation with investors $i(i=1, \ldots, n)$ ordered by declining level of constant relative risk aversion. Then the slope of the aggregate $R R A$ curve relating aggregate $R R A$ to the aggregate dividend approaches zero for high levels of the aggregate dividend. The same is true for very low levels if the constant RRA of investor 1 is higher than twice the constant RRA of every other investor.

This result characterizes situations in which we may observe a locally strong decline in aggregate RRA. It is driven by the condition that the constant RRA of the most risk averse investor is much higher than that of the other 
investors. Then there exists a range of low aggregate dividend in which the most risk averse investor buys a high share of the available claims so that the aggregate RRA approaches her high level of constant RRA. This investor dominates the market in this range. In the range of high dividends, this investor buys a small share of the available claims so that her influence on the market disappears. In this range the least risk averse investor dominates the market. Hence there is a shift from a high risk aversion to a low risk aversion regime. This shift may explain a crash.

The lemma does not prove that in some dividend range aggregate RRA declines very rapidly. We therefore investigate this issue by simulating the equilibrium allocation and the corresponding RRA.

\section{Simulation}

In this section we illustrate our results by some simulations. First, we derive aggregate RRA assuming investors with constant RRA, but the level of RRA varies across investors. Second, we discuss the procedure used for simulation. Third, we present the simulation results.

\subsection{Aggregate Relative Risk Aversion}

The simulation approximates the valuation in an infinite horizon setting by a finite horizon setting. The price of the market portfolio at the horizon is approximated by a function of the aggregate dividend paid at the horizon. Investors trade claims on the dividends paid until the horizon and claims on the horizon market portfolio. Once the stochastic discount factor for the horizon date is known, the stochastic discount factors for the preceding dates can be derived from no-arbitrage. Therefore we need to derive the stochastic discount factor for the horizon date or, equivalently, the aggregate RRA for the horizon date. Assume that there are three investors with different levels of constant relative risk aversion. $\left(\gamma_{1}, \gamma_{2}, \gamma_{3}\right)$ denotes the vector of these levels. We derive the pareto-efficient allocation of claims on the horizon market portfolio by using the social planner model. The planner allocates these claims to the investors so as to maximize the weighted sum of the investors' utility subject to the constraint that the sum of all claims equals the exogenous supply of claims. $\left(1 / \lambda_{i}\right)$ is the state-independent weight attached by the social planner to investor $i . \lambda_{i} / \lambda_{j}$ can be interpreted as the ratio of investor $i$ 's over investor $j$ 's expected marginal utility in equilibrium. $\lambda_{i}$ is higher, the smaller the wealth that investor $i$ allocates to

claims on the horizon market portfolio. Since this wealth is determined by the equilibrium allocation, this is also true of $\lambda_{i}$. Yet, the simulation takes 
$\lambda_{i}$ as exogenous. Later on, sensitivity of the results with respect to $\lambda_{i}$ will be discussed.

As discussed before, empirical results on investors' risk aversion are mixed. To determine the values for the risk aversion parameters we refer to recent empirical estimates of aggregate RRA implied by option prices, but stick to relatively conservative specifications.

-insert Figures 1 to 3 here-

Figures 1 to 3 illustrate the simulation results. The upper graph shows the shares of claims bought by the three investors as a function of the aggregate supply of claims. These shares always add up to 1 . The lower graph shows the implied aggregate RRA as a function of the aggregate supply of claims (fat curve) and an approximation of the fat curve (thin curve) which is used later. Note that the scale of $X$, the aggregate supply of claims, is irrelevant since all investors have constant RRA.

Figure 1 may be viewed as the "normal" case. The three investors have RRA levels $(5 ; 3 ; 1)$. The weights $(1 / \lambda)$ are given by the vector $(1 ; 3 / 5 ; 1)$. As indicated in the upper graph, given a very low aggregate supply of claims, the most risk averse investor 1 buys almost all available claims, but her share declines quickly since, first, investor 2 with RRA 3 quickly raises her share and, second, the least risk averse investor also increases her share gradually. The RRA-vector $(5 ; 3 ; 1)$ violates the condition for a risk aversion regime shift given in Lemma 2. Therefore the slope of the aggregate RRA curve does not approach zero for low levels of supply. The lower graph shows that aggregate RRA is basically a smoothly declining convex curve. Hence, in this setting there is no room for a crash.

In Figure 2 we raise investor 1's RRA from 5 to 20 so that $(\gamma)=(20 ; 3 ; 1)$. $(1 / \lambda)=\left(10^{-3} ; 20 ; 1\right)$ so that the expected marginal utility of investor 1 is very high indicating a small amount of wealth allocated to claims on the horizon market portfolio. Yet the upper graph in Figure 2 shows that she buys almost all claims as long as the supply of claims stays below 1 . The second and third investor come into play at higher supply levels. Therefore aggregate RRA stays almost constant at a level of 20 for the entire $(0 ; 1)$ range of claims supply. Then it declines sharply in the range $(1 ; 1.5)$ and thereafter slowly approaches the level 1, the RRA of the least risk averse investor. Hence this situation paves the ground for a crash. Important is the sharp decline in aggregate RRA. This reflects the high pseudo-variance of the investors' inverse RRA, i.e. the second term in equation (2).

Consider the third example in Figure 3. Now there exist two investors with high RRA 20 resp. 18 and one investor with RRA $1 ;(\gamma)=(20 ; 18 ; 1)$ and 
$(1 / \lambda)=(10 ; 6 ; 1)$. In this case the expected marginal utilities of the highly risk averse investors are relatively low indicating relatively high amounts of wealth allocated to claims on the horizon market portfolio. The lower graph shows that aggregate RRA is almost constant at a level of 19 for a wide range of claims supply $(0 ; 1.3)$. Then it drops sharply to a level of 7 in the range $(1.3 ; 1.8)$ and then gradually approaches the level 1 . The interesting result is that even though the condition stated in Lemma 2 does not hold, aggregate RRA basically stays constant in a wide range of low claims supply. The reason is that the two highly risk averse investors dominate the market and change their shares of claims relatively little implying aggregate RRA to be roughly equal to the average of their risk aversion levels. Again, we may observe a crash.

How robust are the results shown in Figures 2 and 3 ? Additional simulations indicate several properties. First, if as in Figure 3, there are 2 investors such that their levels of RRA are higher than twice the level of the third investor, then the aggregate RRA curve is similar to that in Figure 3. Second, if the weights $(1 / \lambda)$ for the three investors are changed, then the shape of the aggregate RRA curve remains similar, but the low supply range with almost constant aggregate RRA will be shorter or longer depending on the wealth of the most risk averse investors. Third, if there are many investors instead of one with the same constant RRA $\gamma$, this has no effect on aggregate RRA as long as the sum of the $\lambda^{1 / \gamma}$ across these investors stays the same. The intuition is that all investors with the same RRA buy the same portfolio of claims up to multiplicative factors reflecting the levels of their initial endowments.

Therefore, the shape of aggregate RRA shown in Figures 2 and 3 appears to be robust to a wide set of parameter changes. The crucial condition for a sharp decline of aggregate RRA in some range of the supply of claims appears to be that there is a group of investors with high levels of RRA and another group of investors with low levels such that the high levels exceed twice the low levels.

\subsection{Simulation Procedure}

For the simulation of equilibrium price processes we approximate aggregate RRA by approximating the equilibrium stochastic discount factor through a sum of power functions. Let $S_{t+h}$ be the value of the market portfolio at some horizon date $t+h$ which defines the aggregate supply of claims at that date. The random part of the stochastic discount factor, $\Phi_{t, t+h}\left(S_{t+h}\right)$, is approximated by the generalized polynomial

$$
\Phi_{t, t+h}=\frac{\sum_{i=1}^{N} \alpha_{i} S_{t+h}^{-\delta_{i}}}{E\left[\sum_{i=1}^{N} \alpha_{i} S_{t+h}^{\left.-\delta_{i} \mid D_{t}\right]}\right.},
$$




\begin{tabular}{|rrrr||rrrr|||crrr|}
\hline \multicolumn{3}{|c||}{ Figure 1} & \multicolumn{5}{|c||}{ Figure 2} & \multicolumn{4}{c|}{ Figure 3 } \\
\hline$\gamma_{1}$ & 5 & $\delta_{1}$ & 4.5 & $\gamma_{1}$ & 20 & $\delta_{1}$ & 20 & $\gamma_{1}$ & 20 & $\delta_{1}$ & 19 \\
$\gamma_{2}$ & 3 & $\delta_{2}$ & 3 & $\gamma_{2}$ & 3 & $\delta_{2}$ & 12 & $\gamma_{2}$ & 18 & $\delta_{2}$ & 6 \\
$\gamma_{3}$ & 1 & $\delta_{3}$ & 1.2 & $\gamma_{3}$ & 1 & $\delta_{3}$ & 2 & $\gamma_{3}$ & 1 & $\delta_{3}$ & 2 \\
\hline$\lambda_{1}^{-1}$ & 1 & $\alpha_{1}$ & 1 & $\lambda_{1}^{-1}$ & $10^{-3}$ & $\alpha_{1}$ & 1 & $\lambda_{1}^{-1}$ & 10 & $\alpha_{1}$ & 1 \\
$\lambda_{2}^{-1}$ & .6 & $\alpha_{2}$ & 1 & $\lambda_{2}^{-1}$ & 20 & $\alpha_{2}$ & 1 & $\lambda_{2}^{-1}$ & 6 & $\alpha_{2}$ & 0.001 \\
$\lambda_{3}^{-1}$ & 1 & $\alpha_{3}$ & .2 & $\lambda_{3}^{-1}$ & 1 & $\alpha_{3}$ & .01 & $\lambda_{3}^{-1}$ & 1 & $\alpha_{3}$ & 0.0001 \\
\hline
\end{tabular}

Table 1: For each figure the table shows the RRA of the three investors $(\gamma)$ and their relative expected marginal utility $\left(\lambda^{-1}\right)$. The parameters used in the polynomial approximation of the stochastic discount factor are the exponents $(\delta)$ and the weights $(\alpha)$.

with $\alpha_{i}, \delta_{i} \in \mathbb{R}$. This specification is quite general. Since the $\delta_{i}$ 's are not required to be integers, this approximation is at least as good as a Taylorseries approximation. We use polynomials with $N=3$ terms. Table 1 displays for each figure of the previous section the parameters of the investors and the parameters $\delta_{i}$ and $\alpha_{i}$ used in the generalized polynomial.

The table shows that the exponents $\delta_{1}$ and $\delta_{3}$ used in the polynomial approximation of the stochastic discount factor correspond closely to the RRA $\gamma_{1}$ resp. $\gamma_{3}$. The quality of the approximation can be seen in the lower graphs of Figures 1 to 3 depicting aggregate RRA derived from the social planner model (fat curve) and aggregate RRA derived from the approximation (thin curve). The approximation appears to be quite good. It could be further improved by using more than three power functions (see also Düring and Lüders, 2005).

The simulation of the process of the price of the market portfolio can be facilitated strongly if the price at any time can be derived analytically. To achieve this, we approximate the infinite horizon setting by a finite horizon setting. The date $t$-price of the market portfolio is the present value of future dividends. We approximate this value by the present value of dividends until a given horizon $t+h$ and a suitable approximation for the horizon wealth generated by subsequent dividends. The horizon $h$ is constant over time so that $t+h$ moves over time. The asset price at the horizon is a deterministic function of the dividend paid at the horizon, $S_{t+h}=S_{t+h}\left(D_{t+h}\right)$ consistent with the infinite horizon model. The approximation used here is that at the horizon the elasticity of the asset price with respect to the dividend is assumed to be constant, i.e. $S_{t+h}=d p D_{t+h}^{\vartheta}$. dp is a kind of price dividend ratio. The exponent $\vartheta$ is assumed to be greater or equal to 1 indicating declining or constant aggregate RRA (see Proposition 1). Since we use a very long horizon of 240 months, we expect the impact of this approximation on our simulation results to be very small. ${ }^{13}$

\footnotetext{
${ }^{13}$ Further numerical simulations based on a finite horizon model that are not shown in
} 
Analyzing the annual S\&P 500 real price and price-dividend data for the time period 1871-2002 ${ }^{14}$, one finds that the price-dividend ratio is reasonably approximated by $\frac{S_{t}}{A D_{t}}=7.27 A D_{t}^{0.53}$ with an $R^{2}$ of almost 40 percent where $A D_{t}=12 D_{t}$ is the annual and $D_{t}$ the monthly dividend . This implies for the numerical simulation based on monthly data $S_{t+h}=325.6 D_{t+h}^{1.53}$. The real interest rate is set to 2.5 percent p.a. which is consistent with the historical average (see Brennan and Xia, 2002). Consistent with the historical mean and volatility of real monthly dividend growth we choose $\sigma_{D}=0.037$ and $\mu_{D}=0.002$. The initial dividend $D_{0}$ is set to 1 or 4 . The asset price is given by the present value of future dividends:

$$
\begin{aligned}
S_{t} & =\sum_{s=t}^{t+h} \exp \left(r_{f}(t-s)\right) E\left(D_{s} \Phi_{t, s} \mid D_{t}\right) \\
& +\exp \left(-r_{f} h\right) E\left(d p D_{t+h}^{\vartheta} \Phi_{t, t+h} \mid D_{t}\right)
\end{aligned}
$$

Using the stochastic discount factor polynomial, $E\left(S_{t+h} \Phi_{t, t+h} \mid D_{t}\right)$ is a weighted average of means of power functions of $S_{t+h}$. Since $S_{t+h}$ is a power function of $D_{t+h}$ and $D_{t+h}$ is lognormally distributed, $E\left(S_{t+h} \Phi_{t, t+h} \mid D_{t}\right)$ can be derived analytically. The same is true of $E\left(D_{s} \Phi_{t, s} \mid D_{t}\right)$ since $\Phi_{t, s}=$ $E\left(\Phi_{t, t+h} \mid D_{s}\right)$ by no-arbitrage. Hence the price $S_{t}$ can be derived analytically as a function of the dividend $D_{t}$ as shown in the appendix. Since the stochastic discount factor $\Phi_{t, t+h}$ is assumed to be time-homogeneous, the asset pricing function (7) is also time-homogeneous. The asset price is a function of the dividend only.

We use simulation to derive the properties of the price process. In each simulation run, we generate 240 observations of the dividend process. This corresponds to 20 years of monthly data. Given a constant investment horizon of $h=240$ months, we obtain a sequence of 240 asset prices, derived from equation (7). For every model specification we run 1000 simulations. The parameters of every specification 1 to 3 are given in Table 1, approximating aggregate RRA in Figures 1 to 3.

\subsection{Simulation Results}

First, consider Figure 4 illustrating the relationship between the asset price and the concurrent dividend.

- insert Figure 4 here -

\footnotetext{
this paper support this view.

${ }^{14}$ Source: Shiller (http://www.econ.yale.edu/ shiller/data.htm)
} 
In the benchmark case of constant aggregate RRA the asset price increases linearly in the dividend. In specification 1, the rather mild decline in aggregate RRA produces a convex curve which mildly contrasts with the benchmark case. Specifications 2 and 3 deviate strongly from the benchmark case. For low dividends, the asset price increases very little with the dividend, then around a dividend level of 4 , it increases strongly and, thereafter, it increases almost proportionally as in the benchmark case. Hence, specifications 2 and 3 show the potential for a stock market crash, in contrast to the benchmark case and specification 1 . If, given specification 3 , the dividend declines from 4.3 to 3.8 , then the price of the market portfolio crashes from about 1,400 to around 260. A small decline (less than 12 percent) in the dividend, the fundamental variable, triggers a very strong decline in the market value (more than 80 percent). The reason is that the stock market switches from a low to a high risk aversion regime. The mildly risk averse investors dominating the market in the high dividend range basically disappear from the market and the very risk averse investors take over and dominate the market. They strongly pull down the asset price. If the dividend happens to first increase from 3.8 to 4.3 and then to fall back to 3.8 , then the asset price increases from about 260 to 1,400 and then falls back to about 260. This can be viewed as a bubble. Technicians would call 260 a support level and 1,400 a resistance level.

The crash potential of specifications 2 and 3 is also illustrated by the strong variability in the elasticity of the asset price with respect to the dividend as shown in Figure 5. This elasticity varies only little with levels between 1 and 2 in specification 1, but it increases dramatically to more than 16 in specifications 2 and 3 around a dividend level of 4 so that the local return volatility will be quite high.

- insert Figure 5 here -

Figure 4 also illustrates return predictability. This exists if expected asset returns depend on the dividend level or on the asset price. In Figure 4, the expected asset return is reflected in the slope of the asset price curve. This slope varies except for the benchmark case, its variation is particularly strong for specifications 2 and 3, due to the crash potential. Another indicator of predictability is the Sharpe-ratio. The simulation shows that except for the benchmark case the Sharpe-ratio declines with increasing dividend, similar to the aggregate RRA. This decline is particularly strong for specifications 2 and 3.

Although the equity premium puzzle is not at the center of our study we would like to point out that declining aggregate RRA may also explain this puzzle. Note that for declining aggregate RRA Sharpe ratios are high for 
low dividend levels and low for high dividend levels. For instance, for Specification 3 the average Sharpe ratio is around 0.18 given an initial dividend $D_{0}=4$. For $D_{0}=1$, we find an astonishingly high average Sharpe ratio of about 2.65. These fluctuations of the Sharpe ratio may explain why for certain time periods empirical studies find such high equity premia.

- insert Table 2 here -

More information on the characteristics of the asset price process is provided in Table 2. This table presents measures of return volatility and of autocorrelation in returns and return volatility for the benchmark case and for specifications 1 to 3 . The results are given for initial dividends of 1 and 4 . The initial dividend is relevant since it determines the likely dividend paths underlying the simulation results. Regarding return predictability, the autocorrelation of returns is important. All displayed return autocorrelations are negative. Figure 6 reveals that the serial return covariance is slightly negative everywhere for specification 1 , but this is not true for specifications 2 and 3. Here the autocorrelation becomes positive at a dividend level of about 3.5, reaches a peak at about 3.7 resp. 3.9 and then turns strongly negative before it moves back close to zero. The intuition for this surprising result is as follows. When the dividend moves up from, say, 3.8 to 4.2 , then the asset return is strongly positive as it is when the dividend moves further up in the next period from 4.2 to 4.7 implying positive autocorrelation. But when it moves further up from 4.7 to 5.2, then the return will be small implying negative autocorrelation. Hence even though Table 2 shows negative autocorrelations, this only indicates that the local negative autocorrelations dominate the positive ones in our simulations. These results seem to be in line with empirical research suggesting short-term momentum and long-term reversals. ${ }^{15}$

- insert Figure 6 here -

Finally, Table 2 illustrates excess volatility and volatility clustering. The volatility of asset returns equals the dividend volatility of 12.8 percent in the benchmark case. But it is higher for specifications 1 to 3 because of declining aggregate RRA. For specification 1 and an initial dividend of 1 the return volatility is 16.7 percent on a monthly basis and 16.6 percent on a 4-year basis. These figures are higher for specifications 2 and 3. They increase dramatically if the initial dividend is 4 , i.e. in the center of the crash potential. The strong price movements in this region produce a predictable, high volatility. All the autocorrelations in return volatility shown in the last

\footnotetext{
${ }^{15}$ There are different definitions of momentum and reversals. In this paper we define positive [negative] serial correlation as momentum [reversal].
} 
two rows of Table 2 are positive indicating volatility clustering. Again, this does not rule out varying signs of local autocorrelation. The autocorrelations are small for specification 1 , but quite high for specifications 2 and 3 . The high volatility in the crash region reinforces volatility clustering. To conclude, this section has demonstrated that declining aggregate RRA makes excess returns overreact, makes expected excess returns and return volatilities predictable, generates excess return volatility and volatility clustering, and, perhaps most importantly, can explain stock market crashes.

\section{Conclusion}

This paper argues that in a perfect capital market with rational, heterogeneously risk averse investors asset pricing is likely to be characterized by declining aggregate relative risk aversion (RRA). Therefore the paper analyzes the impact of declining aggregate RRA on asset returns in a simple rational expectations model. If aggregate RRA is constant and the aggregate dividend is the fundamental variable, driven by a geometric Brownian motion, then asset prices are also governed by a geometric Brownian motion. Declining aggregate RRA can lead to short-term momentum, long-term reversals as well as high and persistent volatility of excess returns. Declining aggregate RRA even provides a rationale for chart analysis in an efficient market. The asset price reaction to a dividend change depends on the dividend level. In certain dividend ranges the asset price reaction is weak while it can be quite strong in others. A small decline in the dividend can trigger a strong decline in the price of the market portfolio as in a stock market crash. This requires that aggregate RRA declines strongly in some dividend range. It is likely to happen when there are two groups of investors, one with a high level of RRA and the other one with a much lower level. Hence explaining a stock market crash neither requires "irrational behavior" nor market imperfections.

The findings of the paper are consistent with many empirical findings on stock returns. In contrast to mainly empirically motivated time-series models, the model in this paper has a solid economic foundation and in contrast to many theoretical models analytical asset price functions are derived. However, the model setup is deliberately chosen to be simple to pinpoint the importance of aggregate RRA for asset return processes. Therefore future research is needed to investigate more complicated models taking into consideration more realistic settings. For example, this model does not deal explicitly with heterogeneous expectations of investors. Also, this model only analyzes the return of the market portfolio neglecting single stocks. 


\section{Appendix}

\subsection{Proof of Lemma 1}

Investor $i$ derives her optimal portfolio of date $\tau$-claims from

$$
\max E\left[u_{i}\left(x_{i}\right)\right] \quad \text { s.t. } \quad E\left[x_{i} \phi\left(D_{\tau}\right)\right]=w_{0 \tau} .
$$

$w_{0 \tau}$ is the investor's endowment reserved for buying claims on $D_{\tau} . \phi\left(D_{\tau}\right)$ is the stochastic discount factor, i.e. $\phi\left(D_{\tau}\right)=\Phi_{0, \tau} \exp \left(-r_{f} \tau\right)$. The FOC for $x_{i}$ is $\left(\lambda_{i}\right.$ denotes the Lagrange-multiplier of the budget constraint)

$$
u_{i}^{\prime}\left(x_{i}\right)=\lambda_{i} \phi\left(D_{\tau}\right) \quad ; \forall D_{\tau}
$$

Differentiate the $\log$ of this equation with respect to $\ln D_{\tau}$. This yields

$$
\eta_{i}\left(x_{i}\right) \frac{d \ln x_{i}}{d \ln D_{\tau}}=\eta_{M}\left(D_{\tau}\right) \quad ; \forall D_{\tau}
$$

Since $d \ln x_{i} / d \ln D_{\tau}=\left(d x_{i} / d D_{\tau}\right) / \alpha_{i}\left(D_{\tau}\right)$ and $\sum_{i} d x_{i} / d D_{\tau}=1$, aggregating equation (8) across all investors yields

$$
\frac{1}{\eta_{M}\left(D_{\tau}\right)}=\sum_{i} \frac{\alpha_{i}\left(D_{\tau}\right)}{\eta_{i}\left(x_{i}\right)}
$$

Differentiate equation (9) with respect to $D_{\tau}$. This yields

$$
\frac{\eta_{M}^{\prime}\left(D_{\tau}\right)}{\left[\eta_{M}\left(D_{\tau}\right)\right]^{2}}=\sum_{i} \frac{\eta_{i}^{\prime}\left(x_{i}\right)}{\left[\eta_{i}\left(x_{i}\right)\right]^{2}} \frac{d x_{i}}{d D \tau} \alpha_{i}\left(D_{\tau}\right)-\sum_{i} \frac{1}{\eta_{i}\left(x_{i}\right)} \alpha_{i}^{\prime}\left(D_{\tau}\right)
$$

The first term on the right hand side of equation (10) can be rewritten using (8) as

$$
\sum_{i} \frac{\eta_{i}^{\prime}\left(x_{i}\right)}{\left[\eta_{i}\left(x_{i}\right)\right]^{2}} \frac{d \ln x_{i}}{d \ln D_{\tau}}\left[\alpha_{i}\left(D_{\tau}\right)\right]^{2}=\frac{1}{\eta_{M}\left(D_{\tau}\right)} \sum_{i} \frac{\eta_{i}^{\prime}\left(x_{i}\right)}{\eta_{i}\left(x_{i}\right)}\left[\alpha_{i}\left(D_{\tau}\right) \frac{\eta_{M}\left(D_{\tau}\right)}{\eta_{i}\left(x_{i}\right)}\right]^{2}
$$


The second term on the right hand side of equation (10) can be rewritten as (since $\left.\sum_{i} \alpha_{i}^{\prime}\left(D_{\tau}\right)=0\right)$

$$
\begin{aligned}
\sum_{i} \alpha_{i}^{\prime}\left(D_{\tau}\right)\left(\frac{1}{\eta_{i}\left(x_{i}\right)}-\frac{1}{\eta_{M}\left(D_{\tau}\right)}\right) & =\frac{1}{D_{\tau}} \sum_{i} \frac{\alpha_{i}^{\prime}\left(D_{\tau}\right)}{\alpha_{i}\left(D_{\tau}\right)} D_{\tau}\left[\frac{1}{\eta_{i}\left(x_{i}\right)}-\frac{1}{\eta_{M}\left(D_{\tau}\right)}\right] \alpha_{i}\left(D_{\tau}\right) \\
& =\frac{1}{D_{\tau}} \sum_{i} \frac{d \ln \alpha_{i}}{d \ln D_{\tau}}\left[\frac{1}{\eta_{i}\left(x_{i}\right)}-\frac{1}{\eta_{M}\left(D_{\tau}\right)}\right] \alpha_{i}\left(D_{\tau}\right) \\
& =\frac{\eta_{M}\left(D_{\tau}\right)}{D_{\tau}} \sum_{i}\left[\frac{1}{\eta_{i}\left(x_{i}\right)}-\frac{1}{\eta_{M}\left(D_{\tau}\right)}\right]^{2} \alpha_{i}\left(D_{\tau}\right)
\end{aligned}
$$

The last equation follows from $d \ln \alpha_{i} / d \ln D_{\tau}=d \ln x_{i} / d \ln D_{\tau}-1$ and equation (8) which implies $d \ln \alpha_{i} / d \ln D_{\tau}=\eta_{M}(D \tau)\left[1 / \eta_{i}\left(x_{i}\right)-1 / \eta_{M}\left(D_{\tau}\right)\right]$.

Multiplying equation (10) by $\eta_{M}\left(D_{\tau}\right)$ proves Lemma 1 .

\subsection{Proof of Proposition 1}

For $0 \leq t \leq s$ the forward stochastic discount factor is defined by $\Phi_{t, s}=$ $\Phi_{0, s} / \Phi_{0, t}$. Because of the martingale property $\Phi_{0, t}=E\left(\Phi_{0, s} \mid D_{t}\right)$, the elasticity of the (forward) stochastic discount factor $\Phi_{t, s}$ with respect to the dividend $D_{t}$ is given by

$$
\frac{\partial \ln \Phi_{t, s}}{\partial \ln D_{t}}=\frac{\partial \ln \Phi_{0, s}}{\partial \ln D_{s}}-E\left(\frac{\partial \ln \Phi_{0, s}}{\partial \ln D_{s}} \Phi_{t, s} \mid D_{t}\right)=-\eta_{s}^{\Phi, D}+E\left(\eta_{s}^{\Phi, D} \Phi_{t, s} \mid D_{t}\right),
$$

since $\frac{\partial \ln D_{s}}{\partial \ln D_{t}}=1$ and $\eta_{s}^{\Phi, D} \equiv-\frac{\partial \ln \Phi_{0, s}}{\partial \ln D_{s}}$.

Differentiating the logarithm of equation (4) with respect to $\ln D_{t}$ yields after some manipulation

$$
\eta_{t}^{S, D}=1+\frac{\int_{t}^{\infty} \exp \left(-r_{f}(s-t)\right) E\left(D_{s} \Phi_{t, s}\left(-\eta_{s}^{\Phi, D}+E\left(\eta_{s}^{\Phi, D} \Phi_{t, s} \mid D_{t}\right)\right) \mid D_{t}\right) d s}{S_{t}} .
$$

The forward stochastic discount factor defines an equivalent martingale measure $\widetilde{P}$, i.e. $\widetilde{P}(A)=\int_{A} \Phi_{t, s} d P$, where $P$ is the physical or objective probability measure. Hence the previous equation yields

$$
\eta_{t}^{S, D}=1-\int_{t}^{\infty} \frac{\operatorname{cov}^{\widetilde{P}}\left(D_{s}, \eta_{s}^{\Phi, D} \mid D_{t}\right) d s}{\exp \left(r_{f}(s-t)\right) S_{t}}
$$

where $\operatorname{cov}^{\widetilde{P}}($.$) is the covariance under the equivalent martingale measure \widetilde{P}$. Thus, if $\eta_{s}^{\Phi, D}$ is constant, then $\eta_{t}^{S, D} \equiv \frac{\partial \ln S_{t}}{\partial \ln D_{t}}=1$. Declining aggregate RRA, $\frac{\partial \eta_{s}^{\Phi, D}}{\partial D_{s}}<0$, implies $\operatorname{cov}^{\widetilde{P}}\left(D_{s}, \eta_{s}^{\Phi, D} \mid D_{t}\right)<0$ and, hence, $\eta_{t}^{S, D}>1$. Increasing aggregate RRA, $\frac{\partial \eta_{s}^{\Phi, D}}{\partial D_{s}}>0$, implies $\eta_{t}^{S, D}<1$. 


\subsection{Proof of Proposition 2}

We know that for constant aggregate RRA

$$
\operatorname{Var}\left(\ln \frac{V_{\tau}}{V_{t}} \mid D_{t}\right)=\operatorname{Var}\left(\ln \frac{D_{\tau}}{D_{t}} \mid D_{t}\right), t<\tau
$$

By Proposition 1, for declining aggregate RRA $\eta_{t}^{\Phi, D}$, the elasticity $\eta_{t}^{S, D}>1$ so that the conditional variance of asset returns is higher than the (conditional) variance of the dividend process, i.e.

$$
\operatorname{Var}\left(\ln \frac{V_{\tau}}{V_{t}} \mid D_{t}\right)>\operatorname{Var}\left(\ln \frac{D_{\tau}}{D_{t}} \mid D_{t}\right), \quad t<\tau .
$$

Consider now the unconditional variance (i.e. $\theta=0$ ):

$$
\operatorname{Var}\left(\ln \frac{V_{\tau}}{V_{t}}\right)=\operatorname{Var}\left(E\left(\ln V_{\tau} \mid D_{t}\right)-\ln V_{t}\right)+E\left(\operatorname{Var}\left(\ln V_{\tau} \mid D_{t}\right)\right)
$$

with

$$
E\left(\ln V_{\tau} \mid D_{t}\right)-\ln V_{t}=E\left(\int_{t}^{\tau}\left(\mu_{V}\left(S_{s}\right)-\frac{1}{2} \Sigma_{V}\left(S_{s}\right)^{2}\right) d s \mid D_{t}\right)
$$

We need to show that $\operatorname{Var}\left(\ln \frac{V_{\tau}}{V_{t}}\right)$ is greater than

$$
\operatorname{Var}\left(\ln \frac{D_{\tau}}{D_{t}}\right)=\operatorname{Var}\left(\ln D_{\tau} \mid D_{t}\right)
$$

From (11) it follows that the second term on the right hand side of equation (12) exceeds $\operatorname{Var}\left(\ln \frac{D_{\tau}}{D_{t}}\right)$. As the first term on the right hand side of equation (12) is also positive, we are done. The proof is the same for the variance conditional on $D_{\theta} ; 0<\theta<t$.

\subsection{Proof of Proposition 3}

Since by definition $C E R_{t, \tau} \equiv \int_{t}^{\tau}\left(d S_{s} / S_{s}\right)+\int_{t}^{\tau}\left(D_{s} / S_{s}-r_{f}\right) d s$, and the riskless rate $r_{f}$ is assumed constant, the covariance is given by

$\operatorname{Cov}\left(C E R_{t, \tau}, \mu_{V}\left(S_{\tau}\right)-r_{f} \mid D_{t}\right)=\operatorname{Cov}\left(\int_{t}^{\tau} \frac{d S_{s}}{S_{s}}+\int_{t}^{\tau} \frac{D_{s}}{S_{s}} d s, \int_{t}^{\tau} d \mu_{V}\left(S_{s}\right) \mid D_{t}\right)$ 


$$
\begin{gathered}
=E\left(\left[\int_{t}^{\tau} \frac{d S_{s}}{S_{s}}+\int_{t}^{\tau} \frac{D_{s}}{S_{s}} d s-E\left(\int_{t}^{\tau} \frac{d S_{s}}{S_{s}}+\int_{t}^{\tau} \frac{D_{s}}{S_{s}} d s \mid D_{t}\right)\right]\right. \\
\left.\times\left[\int_{t}^{\tau} d \mu_{V}\left(S_{s}\right)-E\left(\int_{t}^{\tau} d \mu_{V}\left(S_{s}\right) \mid D_{t}\right)\right] \mid D_{t}\right)
\end{gathered}
$$

By equation (5), $\mu_{V}\left(S_{t}\right)=\eta_{t}^{\Phi, D} \eta_{t}^{S, D} \sigma_{D}^{2}+r_{f}$ and $\Sigma_{S}\left(S_{t}\right)=\eta_{t}^{S, D} \sigma_{D}$. Since $V_{t}=\alpha_{t} S_{t}$, we obtain $\eta_{t}^{S, D}=\eta_{t}^{V, D}$ and $\Sigma_{V}\left(S_{t}\right)=\Sigma_{S}\left(S_{t}\right)=\eta_{t}^{V, D} \sigma_{D}$. Hence we can rewrite the covariance as

$$
\begin{aligned}
& E\left(\left(\int_{t}^{\tau} \eta_{s}^{V, D} \sigma_{D} d W_{s}\right)\left(\int_{t}^{\tau}\left\{\eta_{s}^{V, D} \frac{\partial \eta_{s}^{\Phi, D}}{\partial D_{s}}+\eta_{s}^{\Phi, D} \frac{\partial \eta_{s}^{V, D}}{\partial D_{s}}\right\} \sigma_{D}^{3} D_{s} d W_{s}\right) \mid D_{t}\right) \\
= & \int_{t}^{\tau} E\left(\left\{\eta_{s}^{V, D} \frac{\partial \eta_{s}^{\Phi, D}}{\partial D_{s}}+\eta_{s}^{\Phi, D} \frac{\partial \eta_{s}^{V, D}}{\partial D_{s}}\right\} \sigma_{D}^{4} D_{s} \eta_{s}^{V, D} \mid D_{t}\right) d s,
\end{aligned}
$$

since by Ito's Lemma the stochastic part of $d \mu_{V}\left(S_{t}\right)$ is given by

$$
\frac{\partial\left(\eta_{t}^{\Phi, D} \eta_{t}^{V, D} \sigma_{D}^{2}+r_{f}\right)}{\partial D_{t}} \sigma_{D} D_{t} d W_{t}
$$

The elasticities $\eta_{s}^{V, D}$ and $\eta_{s}^{\Phi, D}$ are positive. Hence, $\operatorname{Cov}\left(C E R_{t, \tau}, \mu_{V}(V \tau)-r_{f} \mid D_{t}\right)<$ [>] 0 if aggregate RRA is declining [increasing] and $\eta_{s}^{V, D}$ is non-increasing [non-declining] in $D_{s}$. The latter condition is equivalent to the condition that the instantaneous volatility of the return index, $\Sigma_{V}\left(S_{s}\right)$, is not increasing [not declining] because $\Sigma_{V}\left(S_{s}\right)=\eta_{s}^{V, D} \sigma_{D}$.

\subsection{Proof of Lemma 2}

Let $X$ denote the aggregate supply of claims. Then equation (9) yields for $\eta_{i}\left(x_{i}\right)=\gamma_{i}, i=1 \ldots n$

$$
\frac{1}{\eta_{M}(X)}=\sum_{i} \frac{\alpha_{i}(X)}{\gamma_{i}}
$$

Differentiating with respect to $X$ yields

$$
\frac{\eta_{M}^{\prime}(X)}{\left[\eta_{M}(X)\right]^{2}}=\sum_{i} \frac{\alpha_{i}^{\prime}(X)}{\gamma_{i}}
$$


Hence $\eta_{M}^{\prime}(X) \rightarrow 0$ if $\alpha_{i}^{\prime}(X) \rightarrow 0, \forall i$. The first order condition for an optimal portfolio of claims is

$$
x_{i}^{-\gamma_{i}}=\lambda_{i} \cdot \phi(X) ; \forall(i, X)
$$

Hence

$$
\frac{x_{i}}{X}=\alpha_{i}(X)=\lambda_{i}^{-\frac{1}{\gamma_{i}}}[\phi(X)]^{-\frac{1}{\gamma_{i}}} / X
$$

so that $\alpha_{i}(X) \epsilon(0,1)$.

Differentiating $\ln \left(\alpha_{i}(X)\right)$ with respect to $\ln (X)$ yields

$$
\frac{\alpha_{i}^{\prime}(X)}{\alpha_{i}(X)}=\frac{1}{X}\left[\frac{1}{\gamma_{i}} \eta_{M}(X)-1\right]
$$

As shown by Benninga and Mayshar (2000), $\eta_{M}^{\prime}(X)<0$ and for $X \rightarrow \infty$, $\alpha_{n} \rightarrow 1$, so that $\eta_{M}(X) \rightarrow \gamma_{n}$. Hence, for $X \rightarrow \infty, \alpha_{i}^{\prime}(X) \rightarrow 0, \forall i$, and $\eta_{M}^{\prime}(X) \rightarrow 0$

Now consider $X \rightarrow 0$. Then $\eta_{M}^{\prime}(X) \rightarrow 0$ if $\alpha_{i}^{\prime}(X) \rightarrow 0, i=2, . ., n$, since $\sum_{i} \alpha_{i}^{\prime}(X)=0$. From the first order condition, optimal risk sharing implies

$$
x_{i}=\left(\frac{\lambda_{i}}{\lambda_{1}}\right)^{-\frac{1}{\gamma_{i}}} x_{1}^{\frac{\gamma_{1}}{\gamma_{i}}}
$$

or

$$
\frac{x_{i}}{X^{2}}=\frac{\alpha_{i}(X)}{X}=\left(\frac{\lambda_{i}}{\lambda_{1}}\right)^{-\frac{1}{\gamma_{i}}} \frac{x_{1}^{\frac{\gamma_{1}}{\gamma_{i}}}}{X^{2}}
$$

As shown by Benninga and Mayshar (2000), $\alpha_{1}(X) \rightarrow 1$ for $X \rightarrow 0$ so that $\eta_{M}(x) \rightarrow \gamma_{1}$ and $x_{1} \rightarrow X$. Hence the last equation yields for $X \rightarrow 0$

$$
\frac{\alpha_{i}(X)}{X} \rightarrow\left(\frac{\lambda_{i}}{\lambda_{1}}\right)^{-\frac{1}{\gamma_{i}}} X^{\frac{\gamma_{1}}{\gamma_{i}}-2}, i=2, . ., n
$$

This term goes to zero for $X \rightarrow 0$ if $\gamma_{1}>2 \gamma_{i}, i=2, . ., n$. Then, by equation $(1), \alpha_{i}^{\prime}(X) \rightarrow 0$ for $X \rightarrow 0, i=2, \ldots, n$. Hence $\eta_{M}^{\prime}(X) \rightarrow 0$ for $X \rightarrow 0$. 


\subsection{The Price of the Market Portfolio}

The price of the market portfolio at date $t, S_{t}$, is

$$
\begin{aligned}
S_{t}= & \sum_{s=t}^{t+h} \exp \left(r_{f}(t-s)\right) E\left[D_{s} \Phi_{t, s} \mid D_{t}\right)+\exp \left(-r_{f} h\right) E\left(d p D_{t+h}^{\vartheta} \Phi_{t, t+h} \mid D_{t}\right) \\
= & A \sum_{s=t}^{t+h} \exp \left(r_{f}(t-s)\right) \sum_{i=1}^{N} D_{t}^{1-\delta_{i} \vartheta} B_{t, s}^{i} \\
& \exp \left[\left(1-\delta_{i} \vartheta(s-t)\right)\left\{\mu_{D}-\delta_{i} \vartheta \sigma_{D}^{2} / 2\right\}\right] \\
& +A \exp \left(-r_{f} h\right) \sum_{i=1}^{N} D_{t}^{\vartheta\left(1-\delta_{i}\right)} \beta_{i} d p^{1-\delta_{i}} \\
& \exp \left[\left(1-\delta_{i}\right) \vartheta h\left\{\mu_{D}-\left[\left(1-\delta_{i}\right) \vartheta-1\right] \sigma_{D}^{2} / 2\right\}\right]
\end{aligned}
$$

with

$$
\begin{aligned}
A^{-1} & \equiv \sum_{i=1}^{N} D_{t}^{-\delta_{i} \vartheta} B_{t, t}^{i} \\
B_{t, s}^{i} & \equiv \beta_{i} d p^{-\delta_{i}} \exp \left[-\delta_{i} \vartheta(t+h-s)\left\{\mu_{D}-\left[\delta_{i} \vartheta+1\right] \sigma_{D}^{2} / 2\right\}\right]
\end{aligned}
$$




\section{References}

Ait-Sahalia, Y. and A. W. Lo, 2000, Nonparametric Risk Management and Implied Risk Aversion, Journal of Econometrics 94, 9-51.

Ang, A. and J. Liu, 2004, Risk, Return and Dividends, working paper, Columbia University

Barone-Adesi, G., Engel, R. and L. Mancini, 2004, GARCH Options in Incomplete Markets, working paper, University of Lugano.

Bick, A., 1990, On Viable Diffusion Price Processes of the Market Portfolio, Journal of Finance 45, 673-689.

Black, F. and M. Scholes, 1973, The Pricing of Options and Corporate Liabilities, Journal of Political Economy 81, 637-654.

Benninga, S. and J. Mayshar, 2000, Heterogeneity and Option Pricing, Review of Derivatives Research 4, 7-27.

Bliss, R. and N. Panigirtzoglou, 2004, Option-Implied Risk Aversion Estimates, Journal of Finance 59, 407-446.

Brennan, M. J., A. W. Wang and Y. Xia, 2003, Estimation and Test of a Simple Model of Intertemporal Capital Asset Pricing, Journal of Finance, forthcoming.

Brennan, M. J. and Y. Xia, 2002, Stock Price Volatility and the Equity Premium, Journal of Monetary Economics 47, 249-283.

Brennan, M. J. and Y. Xia, 2003, Risk and Valuation Under an Intertemporal Capital Asset Pricing Model, Journal of Business, forthcoming.

Camara, A., 2003, A Generalization of the Brennan-Rubinstein Approach for the Pricing of Derivatives, Journal of Finance 58, 805-819.

Campbell, J. Y., A. W. Lo and A. C. MacKinlay, 1997, The Econometrics of Financial Markets, Princeton University Press. 
Chan, Y. L. and Kogan, L., 2002, Catching Up with the Joneses: Heterogeneous Preferences and the Dynamics of Asset Prices, Journal of Political Economy 110, 1255-1285.

Cochrane, J. H., 2001, Asset Pricing, Princeton University Press.

David, A., 1997, Fluctuating Confidence in Stock Markets: Implications for Returns and Volatility, Journal of Financial and Quantitative Analysis 32, 427-462.

Dittmar, R. F., 2002, Nonlinear Pricing Kernels, Kurtosis Preference, and Evidence from the Cross Section of Equity Returns, Journal of Finance 57, 369-403.

Düring, B. and E. Lüders, 2005, Option Prices under Generalized Pricing Kernels, Review of Derivatives Research 8, 97-123.

Franke, G., R. C. Stapleton and M. G. Subrahmanyam, 1999, When are Options Overpriced? The Black-Scholes Model and Alternative Characterisations of the Pricing Kernel, European Finance Review 3, 79-102.

Ghysels, E., A. C. Harvey and E. Renault, 1996, Stochastic Volatility, Handbook of Statistics 14, 119-191.

He, H. and H. Leland, 1993, On Equilibrium Asset Price Processes, Review of Financial Studies 6, 593-617.

Hentschel, L., 2003, Errors in Implied Volatility Estimation, Journal of Financial and Quantitative Analysis 38, 779-810.

Jackwerth, J. C., 2000, Recovering Risk Aversion from Option Prices and Realized Returns, Review of Financial Studies 13, 433-451.

Johnson, T. C., 2002, Rational Momentum Effects, Journal of Finance 57, 585-608.

Lengwiler, Y. 2004, Heterogeneous Patience and the Term Structure of Real Interest Rates, American Economic Review forthcoming. 
LeRoy, S. and R. Porter, 1981, The Present Value Relation: Tests Based on Variance Bounds, Econometrica 49, 555-574.

Lo, A. W., H. Mamaysky and J. Wang, 2000, Foundations of Technical Analysis: Computational Algorithms, Statistical Inference, and Empirical Implementation, Journal of Finance 55, 1705-1765.

Pastor, L. and P. Veronesi, 2003, Stock Valuation and Learning about Profitability, Journal of Finance 58, 1749-1789.

Rosenberg, J. V. and R. F. Engle, 2002, Empirical Pricing Kernels, Journal of Financial Economics 64, 341-372.

Rubinstein, M., 1974, An Aggregation Theorem for Securities Markets, Journal of Financial Economics 1, 225-244.

Shiller, R. J., 1981, Do Stock Prices Move Too Much, to be Justified by Subsequent Changes in Dividends?, American Economic Review 71, 421436 .

Shiller, R. J., 2000, Irrational Exuberance, Princeton University Press.

Stapleton, R. C. and M. G. Subrahmanyam, 1990, Risk Aversion and the Intertemporal Behavior of Asset Prices, Review of Financial Studies 3, 677693.

Timmermann, A. G., 1993, How Learning in Financial Markets Generates Excess Volatility and Predictability of Stock Returns, Quarterly Journal of Economics 108, 1135-1145.

Veronesi, P., 2000, How does Information Quality Affect Stock Returns, Journal of Finance 55, 807-837.

Wachter, J., 2002, Portfolio and Consumption Decisions under Mean-Reverting Returns: An Exact Solution for Complete Markets, Journal of Financial and Quantitative Analysis 37, 63-91. 


\section{Figures}

Figures 1 to 3 depict in the upper graph the shares of claims bought by the three investors in equilibrium for different levels of aggregate supply of claims, X. The fat (thin) curve in the lower graph depicts the implied (approximated) aggregate RRA with respect to X. $(\gamma)$ denotes the assumed vector of the constant RRA of the three investors, $(1 / \lambda)$ denotes the vector of weights attached to these investors by the social planner.
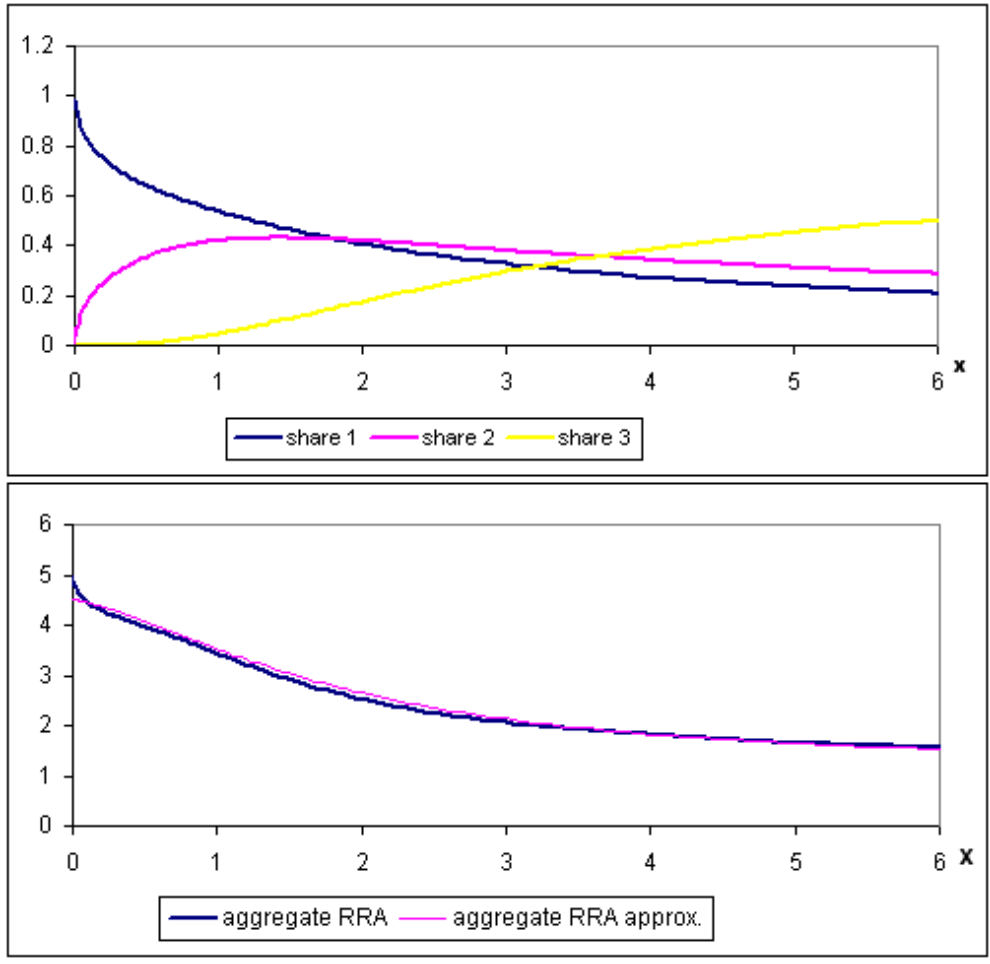

Figure $1:(\gamma)=(5 ; 3 ; 1)$ and $1 / \lambda=(1 ; 3 / 5 ; 1)$ 

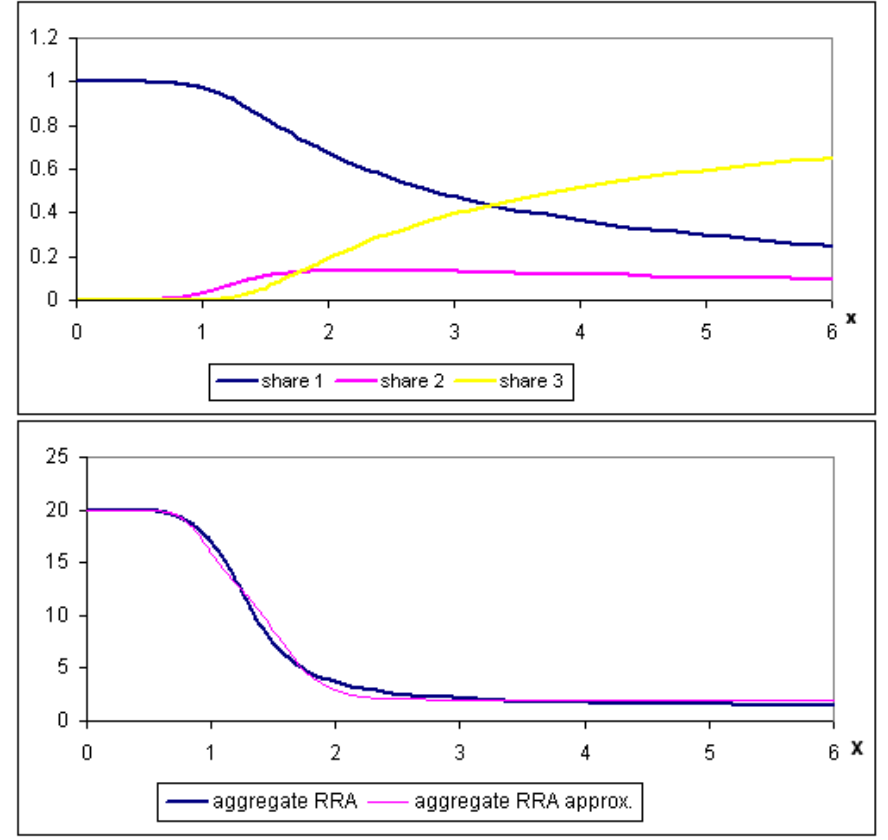

Figure $2:(\gamma)=(20 ; 3 ; 1)$ and $1 / \lambda=\left(10^{-3} ; 20 ; 1\right)$
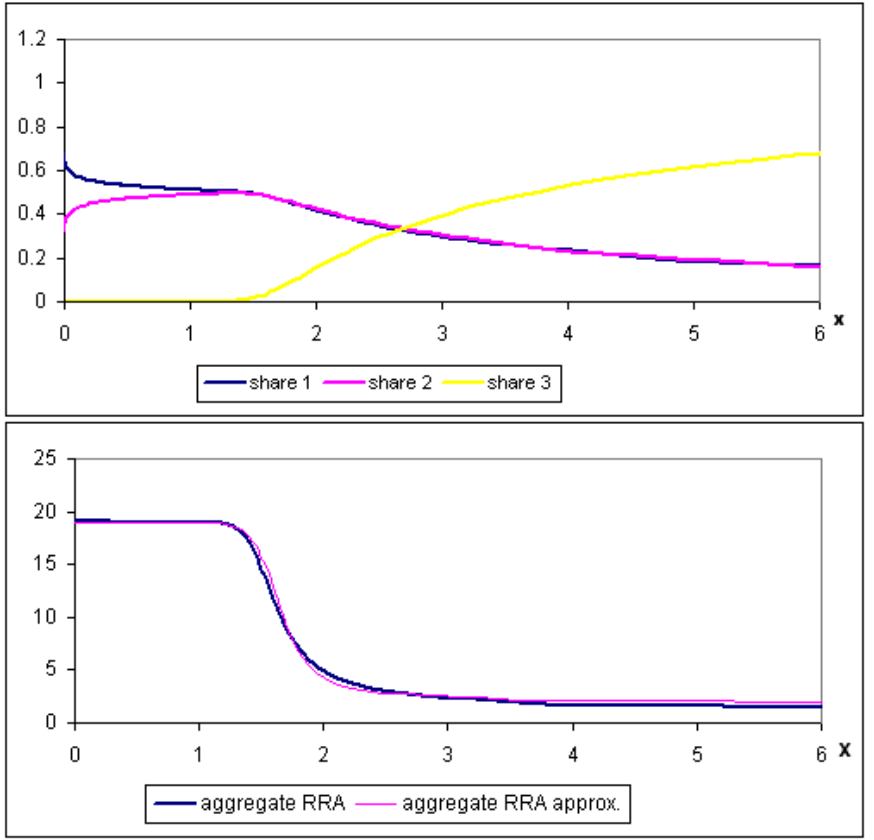

Figure $3:(\gamma)=(20 ; 18 ; 1)$ and $1 / \lambda=(10 ; 6 ; 1)$ 

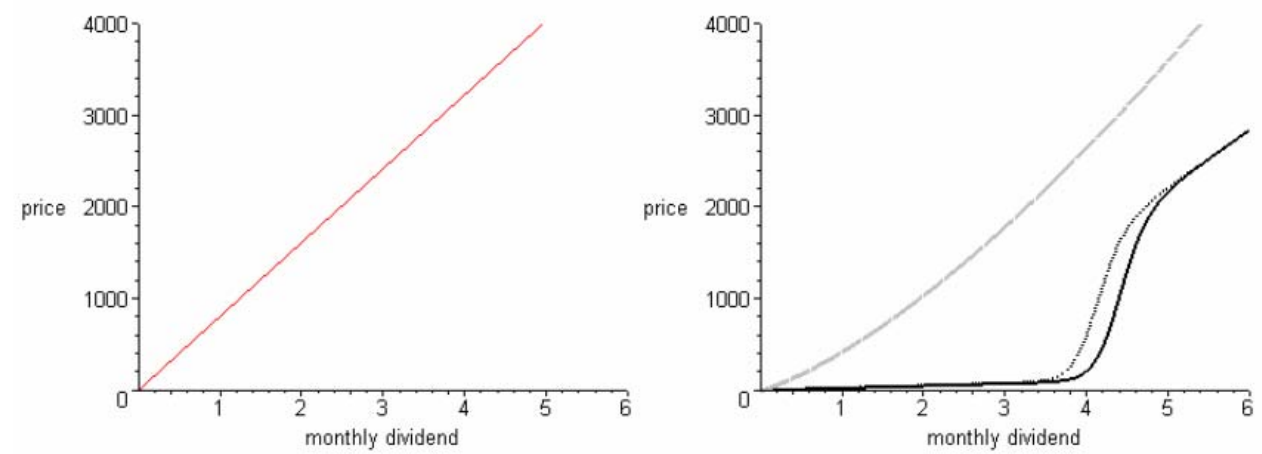

Figure 4: Asset price as a function of the concurrent monthly dividend.

The figure shows for four different specifications the asset price as a function of the concurrent monthly dividend. The first graph (left) shows the benchmark case of constant aggregate RRA. The other graph shows the asset prices for declining aggregate RRA as shown in Specification 1 (gray line), Specification 2 (black line) and Specification 3 (dotted line)(Figure 1-3).

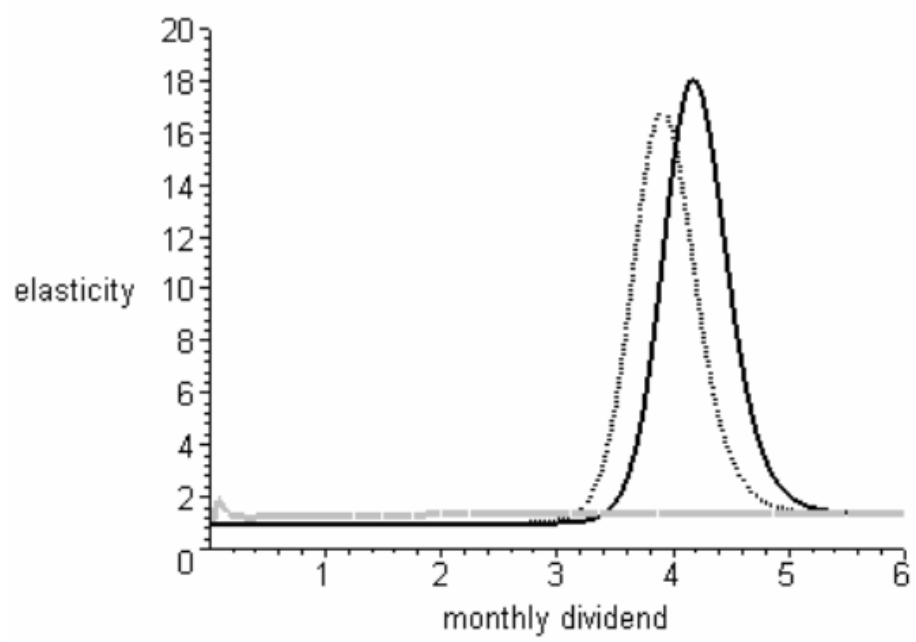

Figure 5: Elasticity of the asset price with respect to the concurrent monthly dividend.

The figure shows the elasticity of the asset price with respect to the concurrent monthly dividend for declining aggregate RRA as shown in Specification 1 (gray line), Specification 2 (black line) and Specification 3 (dotted line) (Figure 1-3). The benchmark case of constant aggregate RRA (not shown in the figure) yields a constant elasticity of 1 . 


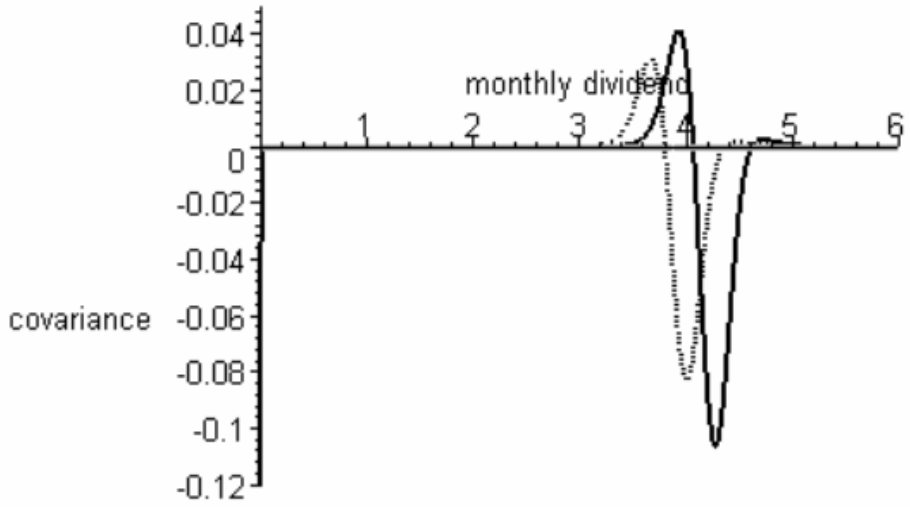

Figure 6: Serial covariance of the asset return as a function of the monthly dividend.

The figure shows the instantaneous serial covariance of the monthly asset return as a function of the monthly dividend for declining aggregate RRA as shown in Specification 1 (gray line), Specification 2 (black line) and Specification 3 (dotted line) (Figure 1-3). In the benchmark case of constant aggregate RRA there is no serial correlation. The instantaneous serial covariance, $\operatorname{cov}_{t}\left(C E R_{t, \tau}, \mu(\tau)\right)$ with $\tau \rightarrow t$, is the cross variation between the expected excess return and the cumulated excess return.

\begin{tabular}{|l|c|c|c|c|c|c|c|}
\hline & \multicolumn{3}{|c|}{ Start value $\mathrm{D}_{0}=1$} & \multicolumn{3}{c|}{ Start value $\mathrm{D}_{0}=4$} & \multirow{2}{*}{ GBM } \\
\hline Specification: & 1 & 2 & 3 & 1 & 2 & 3 & \multirow{2}{*}{$\begin{array}{l}\text { mean annualized volatility of } \\
\text { monthly returns }\end{array}$} \\
\hline $\begin{array}{l}\text { mean annualized volatility of } \\
\text { 4-year returns }\end{array}$ & 0.167 & 0.192 & 0.201 & 0.178 & 0.843 & 0.774 & 0.128 \\
\hline $\begin{array}{l}\text { mean autocorrelation (lag 1) } \\
\text { of monthly returns }\end{array}$ & -0.002 & -0.015 & -0.011 & -0.002 & -0.028 & -0.023 & 0 \\
\hline $\begin{array}{l}\text { mean autocorrelation (lag 1) } \\
\text { of 4-year returns }\end{array}$ & -0.019 & -0.031 & -0.055 & -0.015 & -0.168 & -0.179 & 0 \\
\hline $\begin{array}{l}\text { autocorrelation (lag 1) in } \\
\text { monthly return volatility }\end{array}$ & 0.064 & 0.900 & 0.890 & 0.006 & 0.966 & 0.964 & 0 \\
\hline $\begin{array}{l}\text { autocorrelation (lag 4) in } \\
\text { monthly return volatility }\end{array}$ & 0.094 & 0.891 & 0.895 & 0.040 & 0.963 & 0.959 & 0 \\
\hline
\end{tabular}

Table 2: Characteristics of excess returns and excess return volatility.

The table shows the mean annualized volatility of monthly and 4-year-returns, the lag 1-serial correlation of these returns as well as lag 1- and lag 4-serial correlations in return volatility. For comparison we also show the theoretical values for a geometric Brownian motion (constant aggregate RRA). Results are shown for two different start values $\left(D_{0}=1\right.$ and $\left.D_{0}=4\right)$ of the dividend process. Specifications 1 to 3 correspond to the aggregate RRA shown in figures 1 to 3 . 